\title{
ENTRE LA ECONOMÍA, LA POLÍTICA Y LA OPINIÓN PÚBLICA: EL NACIMIENTO DE LAS RESEÑAS ECONÓMICAS EN ESPAÑA (1737-1805) ${ }^{1}$
}

Between the economics, politics and public opinion: The birth of reviews on political economy in Spain (1737-1805)

\author{
JESÚS ASTIGARRAGA \\ Universidad de Zaragoza \\ astigarr@unizar.es \\ JAVIER USOZ \\ Universidad de Zaragoza \\ jusoz@unizar.es \\ JUAN ZABALZA \\ Universidad de Alicante \\ zabalza@ua.es
}

Cómo citar/Citation

Astigarraga, J., Usoz, J. y Zabalza, J. (2020).

Entre la economía, la política y la opinión pública: el nacimiento

de las reseñas económicas en España (1737-1805).

Revista de Estudios Políticos, 190, 259-288.

doi: https://doi.org/10.18042/cepc/rep.190.09

\section{Resumen}

La Ilustración europea fue el germen de una opinión pública con relevancia política. En dicho proceso participaron los textos de la naciente ciencia económica. Dichos textos, que se presentaron con formas muy diversas y novedosas, además de servir a la circulación internacional de las ideas económicas actuaron como vehículo

Este trabajo se integra en el Proyecto HAR2016-77344-R. Sus autores agradecen los comentarios realizados por los dos evaluadores anónimos. 
de propaganda sociopolítica. Tal es el caso, hasta la fecha no estudiado, de las reseñas de obras económicas. Estas aparecieron como un género nuevo en las igualmente novedosas revistas, ya fueran generalistas, culturales o propiamente económicas. El presente estudio revisa el conjunto de reseñas económicas publicadas en la prensa espańola del largo siglo XVIII. No es casual que las principales revistas de ese periodo incluyeran dichas reseñas, en consonancia con la importancia que fue adquiriendo la economía política como ciencia de análisis y reforma de la sociedad. A partir de dicha información, e incluyendo a sus protagonistas principales, esta investigación plantea una interpretación general del fenómeno, vinculándolo a la reforma económica y política característica de la Ilustración tardía. Dicha reforma constituirá el caldo de cultivo del cambio del Antiguo Régimen al Estado liberal.

\title{
Palabras clave
}

Economía política; Ilustración española; reformismo político; historia del pensamiento económico; revistas; reseñas económicas.

\begin{abstract}
The European Enlightenment was the origin of the political influence of public opinion. The writings of the fledging economic science were part of this movement. These works took different and modern formats and served as vehicles for the international circulation of economic ideas and socio-political propaganda. So far, this is the case of the still unexplored reviews on political economy, a new genre in the novel journals, whether generalist, cultural or strictly economic. This article analyses the overall reviews on political economy published in the Spanish printing press during the long 18th century. It is no wonder that the leading journals of that period included such reviews following the growing relevance that Political Economy gradually acquired as a science of analysis and reform. The research of these new sources suggests a general interpretation of this phenomenon, linking it to the economic and political reform characteristic of the late Enlightenment. This reform indeed will be the breeding ground for the transition to the liberal state.
\end{abstract}

\section{Keywords}

Political economy; Spanish Enlightenment; political reformism; History of economic thought; journals; reviews on political economy. 


\section{SUMARIO}

I. INTRODUCCIÓN. II. LA PRIMERA ÉPOCA DORADA: NIFO, DE LA BARRERA Y SAURA. III. LA SEGUNDA ÉPOCA DORADA DE LA PRENSA ESPAÑOLA: EL MEMORIAL LITERARIO. IV. LOS PERIÓDICOS RECOPILADORES: EL ESPÍRITU DE LOS MEJORES DIARIOS. V. LA ECONOMÍA POLÍTICA EN LA PRENSA CIENTÍFICA: LAS VARIEDADES DE CIENCIA, LITERATURA Y ARTES. VI. LA RESEÑA, INSTRUMENTO DE LA REFORMA SOCIOPOLIITICA ILUSTRADA. BIBLIOGRAFIA.

\section{INTRODUCCIÓN}

Las reseñas de obras de economía política son una innovación del siglo xviII europeo, de la que España no fue una excepción. Por su contenido y por su forma, que incluye presentaciones diversas, las reseńas publicadas en la prensa periódica — otro fenómeno innovador del periodo- constituyen un nuevo género cuya aparición coincidió, no por casualidad, con la irrupción de otros subgéneros, como los prólogos de las obras económicas, los discursos acerca de la utilidad de las obras económicas o ciertas obras con trasfondo sociopolítico y económico que combinaban realidad y ficción.

Conforme a lo anterior, el tratamiento que se hace en este trabajo de las reseñas sobre publicaciones económicas se inscribe en una interpretación relativamente reciente por parte de la historia intelectual y del pensamiento económico, según la cual las ideas económicas constituyen una parte esencial de la renovación del discurso político de la Ilustración europea (Robertson, 2005, 2013). Esta característica es particularmente cierta y significativa respecto a aquellos contextos, como el español, en los que las ideas políticas tuvieron más dificultades de las que de por sí tenían en ámbitos menos refractarios a las reformas para expresarse en sus términos más trasformadores y radicales.

Respecto a dicha función política, tal y como reflejan más expresamente otros trabajos (Usoz, 2011, 2013, 2015; Astigarraga-Usoz, 2019), la difusión de las ideas económicas durante el siglo XviII estuvo relacionada con la propaganda destinada a preconizar una "nueva política», la propia del "dulce comercio", de acuerdo con la conocida expresión de Montesquieu, basada en la expansión del comercio y el desarrollo económico, como alternativa a la 
hegemónica y tradicional conquista militar, así como a la vertiente eminentemente hacendística de las reflexiones económicas, característica de la literatura previa a la Ilustración. Sin duda, dicha «nueva política», que tuvo en Inglaterra un modelo frecuentemente expreso, implicó nuevos fines y nuevos instrumentos ligados unos y otros a la promoción de la "felicidad pública», entendida como bienestar material del conjunto de la población y no como enriquecimiento de la dinastía gobernante.

La función propagandística referida anteriormente, ligada a la también aludida cuestión de la esfera pública ilustrada, conecta con la idea más específica de que toda ciencia necesita sus lectores, de lo cual la economía política, lejos de ser una excepción, constituye un ejemplo paradigmático. Su emergencia como una disciplina relativamente autónoma a lo largo del siglo XviII europeo, portadora de nuevos fines y modos políticos, requirió de la creación de un público letrado que se interesase por ella. Sin embargo, mientras ha aumentado nuestro conocimiento de los libros que hicieron creer a los ilustrados europeos que estaba naciendo una nueva ciencia, seguimos ignorando mucho acerca de sus lectores, como si fueran actores pasivos en ese proceso emergente, pese a que fueron los responsables de que la economía política se renovara, divulgara y enseñara, contribuyendo a crear nuevas instituciones que cimentaron su desarrollo futuro.

Como ocurrió en el resto de Europa, la prensa española contribuyó a la creación de esa nueva instancia cultural y sociopolítica que fue el «público» (Habermas, 1989; Chartier, 1987, 1995; Munck, 2001; Melton, 2009), y fue un altavoz de las nuevas disciplinas del programa de la Ilustración. En concreto, la economía política floreció en España a partir de 1760 (Fuentes, 2000; Llombart, 2000: 7-89), coincidiendo con la "primera edad de oro" de la prensa, entre 1758 y 1771, en torno a El Pensador (1762-1767) de José Clavijo Fajardo. Tras una década de silencio, entre 1781 - fecha de fundación de $E l$ Censor (1781-1787) de Cańuelo y Pereira- y 1808 conoció su principal «época dorada» (Sempere, IV, 176-198; Guinard, 1973; Sáiz, 1983; Urzainqui, 1995: 125-216; Larriba, 2013; Le Guellec, 2016). Se forjó entonces la conciencia profesional del periodista, escritor público o diarista en la terminología de la época, y de una comunidad con identidad propia en la república literaria (Álvarez Barrientos, 1990: 29-39). Campomanes, Jovellanos, Sempere, Cabarrús o Foronda exaltaron a la prensa como un instrumento de la Ilustración, es decir, de la instrucción, la crítica y el ejercicio de la razón. También constituía una vía para especializar los conocimientos y divulgarlos. Como explicaba Jovellanos, todo ello dependía de un «nuevo público» que se interesara por estos peculiares "papeles económicos», que se leían en «el café, el tocador de sobremesa o la tertulia» y que aunaban buen estilo y rigor (Jovellanos, 1786: 649). 
La identificación de los lectores de esas pioneras informaciones económicas viene dándose a través de los estudios sobre las bibliotecas privadas y sobre los suscriptores de prensa, si bien esta segunda vía se ciñe al final del siglo XVIII, cuando se generalizó la suscripción (Larriba, 2013: 20-22; Le Guellec, 2016: 24-28; Fuentes, 1990: 223). En este trabajo se sigue una tercera vía: la introducción en la prensa de contenidos destinados a engendrar al nuevo lector de economía política en cuanto emergente agente sociopolítico de la reforma ilustrada. En concreto, se aborda la aparición en la prensa ilustrada española de las reseñas de publicaciones económicas.

Los primeros periódicos de reseñas de libros en Europa datan de finales del siglo XVII, de la mano de autores como Bayle o Mencke, pero el fenómeno maduró en la centuria posterior, contribuyendo a la revolución lectora del siglo xviII, tal y como ha estudiado la historiografía, sea desde el enfoque que relaciona la esfera pública y la historia del libro (Chartier, 1987: 183-239; 1993: 13-40; 1995: 81-106; Munck, 2001: 115-153; Melton, 2009: 107-155), desde la sociología del conocimiento (Burke, 2017: 229-253) o desde la que analiza las relaciones entre la economía y la esfera pública (Astigarraga y Usoz, 2013). En definitiva, se trató de la aparición de un «mercado del juicio crítico» (Chartier, 1995: 176-178).

En el caso de España, las dos publicaciones oficiales del periodo, la Gaceta de Madrid y el Mercurio Histórico y Político, fundados en 1697 y 1738, respectivamente, ofrecían informaciones de los libros publicados en Espańa. La segunda fue cuantitativamente más importante, con una progresiva presencia de referencias económicas (López, 1990: 303-311). Por su parte, las reseñas de tratados económicos fueron ingrediente vertebral de los dos primeros periódicos económicos especializados, el Correo Mercantil de España y sus Indias (1792-1808) (Enciso, 1958), y el Semanario de Agricultura y Artes Dirigido a los Párrocos (1797-1808) (Díez Rodríguez, 1980; Larriba y Dufour, 1997). No obstante, respecto al nuevo lector de economía, fueron decisivas las reseñas de la prensa generalista o cultural, que desde las cabeceras de inicios de los ańos sesenta promovidas por Nifo ya había comenzado a interesarse por esa disciplina (Astigarraga, 2018).

En las próximas líneas se analizan los perfiles de la reseña económica en la Ilustración española². El examen de los periódicos de la época arroja una

2 Sin ánimo de exhaustividad, con el fin de tener una información significativa desde 1737, cuando se publicó en el Diario de los Literatos la reseña que hizo F. M. de Huerta de la obra de A. de Bordázar Proporción de monedas, pesos y medidas (1736), hasta 1805, cuando aparecieron las reseńas de algunas obras de E. B. de Condillac, H. L. Duhamel de Monceau y A. Young, en las Variedades de Ciencia, Literatura y Artes, a 
importante actividad, así como un gran número de autores extranjeros de muy amplio espectro, que fueron difundidos en Espańa a través de este instrumento $^{3}$. La cifra de autores de reseńas es mucho menor. Hemos computado once nombres, junto a una treintena de aportaciones anónimas ${ }^{4}$.

\section{LA PRIMERA ÉPOCA DORADA: NIFO, DE LA BARRERA Y SAURA}

El Diario de los Literatos de España fue el primer periódico español dedicado a la publicación de reseńas. Surgido de los ambientes de la Academia de

cargo de J. Blasco, en el caso del primero, y de J. Álvarez Guerra, en los otros dos, hemos registrado 183 reseñas de obras económicas. El reciente libro de Cavaillon (2019) constituye un marco general imprescindible para el contenido de este trabajo. Para una visión transnacional, véase Pérez y Thébaud-Sorgier (2008).

3 Además de las referidas, dichas reseńas abordan una treintena de obras económicas anónimas o genéricamente procedentes de algunas sociedades económicas o agrarias, como las de Berna, París y Escocia, así como, sobre todo, escritos de los autores siguientes: J. Accarias de Serionne, J. Addison, P. A. Alletz, J. F. Andrezel, J.Banks, A. Young, E. Baudisson, Beguillet, G. Belloni, P. Bertholon, J. F. Bielfeld, J. F. J. Bilhon, H. S. J. Bolingbroke, C. Boutelou, G. B. Brezé, J. P. Brissot de Warville, L. G. Buat-Nançay, R. Cantillon, P. Cantos, G. R. de Carli, N. Chomel, É. Cleirac, S. Cliquot de Blervache, J. A. N. Condorcet, Th. Cooper, F. Coyer, P. Custodi, K. von Dalberg, J. A. De Bry, J. L. De Lolme, M. Delfico, V. Delpuech, N. T. L. Des Essarts, A. L. C. Destutt de Tracy, J. F. P. Deterville, A. Dickson, N. Donato, E. Dumont, P. S. Dupont de Nemours, J. B. DupuyDemportes, A. Duvaure, A. Fabbroni, Ch. de Ferrières, G. Filangieri, D. Froment, R. Fulton, G. M. Galanti, G. Garnier,J. Gee, A. Genovesi, A. Y. Goguet, Gouffier, H. Marquis de Grégoire, T. Guiraudet, W. Guthrie, C. M. Guyon, F. G. von Hartig, F. A. F. von Heinitz, J. C. Herbert, F. Hervé, E. F. von Herzberg, H. C. Hirzel, F. Home, P. D. Huet, D. Hume, J. H. G von Justi, A. La Barthe, P. T. de La Forest, H. Lacombe de Prezel, G. M Lampredi, Ch. Ph. De Lasteyrie, N. G. Le Clerc, A. F. Le Clerc, J. Ch. F. Le Gros, A. S. Le Page du Pratz, J. L. Lecointe-Marsillac, J. F. Lesperat, S. N. H. Linguet, E. Lisle, G. B. de Mably, Mr. Marcandier, F. Mazzei, G. S. de Meilhan, J. Millar, V. R. Mirabeau, T. Monticellli, L. Muratori, J. Necker, P. A. O'Heguerty, F. Pagano, A. Patriot, H. Patullo, J. Pinkerton, I de Pinto, W. Playfair, J. Priestley, G. Th Raynal, G de Réal de Curban, A. Rees, F. Risteau, J. B. R. Robinet, J. B. Rougier de la Bergerie, A. Roux, B. Rozet, F. Rozier, B. Th. Rumford, Mr. Saint-Aubin, Ch. Schedel, Serre de la Tour, D. Sestini, J. Sinclair, A. Smith, A. de Sutières-Sarcey, H. A. Tessier, A. L. Thomas, G. Toaldo, Mr. Valat, D. Vandelli, F. Véron de Forbonnais, H. M. Williams, C. B. Wadström y T. Wright.

4 C. Cladera (61 reseñas), J. Ezquerra (31), F. M. Nipho (23), J. Saura (19), J. Álvarez Guerra (6), F. A. y J. Escartín (4), M. de la Barrera (3), F. M. de la Huerta (1), J. Blasco Negrillo (1) y J. Cubié (1). 
la Historia, editado entre 1737 y 1742 por Francisco Manuel de Huerta, Juan Martínez Salafranca y Leopoldo Jerónimo Puig (Velasco, 2000: 58-65), reflejaba que la producción de libros de economía era todavía exigua en Espańa. Tan solo reseńó el libro sobre aritmética comercial del novator valenciano Antonio Bordázar (Diario de los Literatos, 1737: t. I, 150-179). Esto contrasta con los inicios de los años sesenta, cuando tras dos décadas de silencio volvieron a brotar los periódicos sobre información bibliográfica. En 1763, en la Aduana Crítica (1763: vol. II, 5) se podía leer: «La elección de los buenos libros, y su breve exposición, son los medios más oportunos para enriquecerse en el comercio literario, y en esto consiste principalmente el mérito de los extractos y juicios de las obras que se publican». Esta idea exponía la aspiración de insertar a España en el "comercio literario» de las naciones, propia de la generación de periodistas de los años sesenta, Clavijo, Barberi, Saura y, sobre todo, Nifo.

Es conocida la importancia de Nifo en el origen de la prensa española de la segunda mitad del siglo XVIII (Enciso, 1958; Maestre et al., 2015), pero apenas ha requerido atención su Diario Extranjero (en adelante, DE), semanario efímero dedicado a reseñas. Su creación respondió a los cambios políticos y culturales producidos por la derrota franco-española en la guerra de los Siete Años (1757-1763), que condujo a España a intensificar una política de desarrollo económico. Y ello supuso reconsiderar el valor de las publicaciones económicas, consideradas por las élites ilustradas como una de las razones del auge británico. Nifo ya había abierto un espacio a dicha obras en el Correo General, Histórico, Literario y Económico de la Europa (1763), que comenzó a editar tras la firma del Tratado de París (1763). En su coetáneo DE, el propósito del aragonés era similar, pero más preciso: no solo instigar la edición de «papeles públicos», cuanto también la traducción de las novedades foráneas.

Esta reflexión recorría la «Idea» con la que se iniciaba el DE (Nifo, 1763: n. I). Aludiendo a los franceses, Nifo describía que «ven anunciado un libro, un experimento u otro cualquier esfuerzo de la industria y del juicio; examinan su mérito, y si reconocen que pueden aprovecharlo, lo trasplantan a su suelo». España aún debía pasar de la actitud de «mirones» a la de "actores». Su iniciativa perseguía instigar la emulación y la "envidia», para conseguir que "quienes se dedican a la ociosidad o a unos trabajos puramente especulativos [...] se dedicasen a traducir estos buenos libros» (ibid.: n. VIII, 116). En suma, según Nifo, de la traducción «vendrán todos aquellos provechos que hoy logran los reinos civilizados» (ibid.: n. I). Su DE quedaba así encuadrado en la primera ola de liberalización cultural de Carlos III, sintonizando con la importancia que diversos periodistas (además de Nifo, Barberi, Saura o Clavijo) o escritores políticos (Romà, Arriquíbar, etc.) atribuían a los escritos públicos, conforme a la política que sancionará pocos años después el Fiscal Campomanes en sus 
Discursos (1774 y 1775). No obstante, la particularidad del DE radicaba en la vía escogida: a través de las reseńas bibliográficas confiaba en formar en España «una colección [...] completa de las obras que se han dado a la luz en Europa [...] una Biblioteca [...] del feliz progreso de las ciencias» (ibid.: n. VI, 77).

Nifo empleó fuentes diversas en la composición del DE. No obstante, como dejó entrever (id.; Aduana Crítica, vol. II, 1763, p. 15), siguió el modelo de los Annales Typographiques (1758-1763), semanario parisino de gran calidad y alcance que nació con el triple objetivo de dar a conocer los libros impresos en Europa, analizar brevemente sus contenidos y estimular la crítica (Annales typographiques, n. I, 1759, p. 3) $)^{5}$. Junto a los Annales, Nifo empleó otras influyentes cabeceras de la prensa francesa: Journal des Savants, Nouvelles littéraires, Gacette Littéraire de l'Europe o Journal Oeconomique. Con todo, el primero fue su fuente principal: el aragonés era igual de pulcro que el francés al ofrecer los datos bibliográficos de los libros, traducidos al español. En otras cuestiones, en cambio, se distancia de este modelo. Nifo presentaba otras rúbricas sobre botánica, física, literatura, filosofía moral y un largo etcétera. Además, sus reseñas eran más breves e introducían breves comentarios sobre la utilidad del libro en el contexto español. La vida del DE fue corta, pues fue clausurado en agosto de 1763, tras veintidós números, cinco meses después de iniciado.

El DE fue un canal de divulgación en España de las novedades literarias y científicas europeas que estaban siendo difundidas en Francia. Su raigambre ilustrada es indudable ${ }^{6}$. Algo similar ocurría con sus informaciones sobre la tratadística económica, que respondía a tres grupos principales. El primero incluía recensiones de las memorias de las sociedades económicas más prestigiosas de Europa, como las de Bretańa y Berna, así como de las sociedades de agricultura francesas, como las de París o Lyon, fundadas pocos años antes de la publicación del $\mathrm{DE}$.

El segundo grupo reseñaba textos utilitarios y científico-técnicos, especialmente sobre economía rural, síntoma de la intensa agromanía ilustrada europea que se dio desde mediados de siglo. De ahí la notable presencia en el DE de los libros sobre la «nueva agricultura» franco-británica de Tull y

5 El periódico, mensual a partir de 1760, utilizó seis rúbricas: teología, jurisprudencia, ciencias y artes, bellas letras, historia y miscelánea. Fue modelo por su exquisito celo profesional: las informaciones bibliográficas aparecían en el idioma original y en francés, mediante normas de cita uniformes y de gran modernidad (las informaciones sobre los periódicos extranjeros mencionadas en este trabajo proceden de Sgard [1991]).

6 Sus páginas revisaron textos de Mably, Wolff, Hume, La Chalotais, Saverien, Guyon y tantas otras figuras que estaban liderando la renovación de sus respectivas disciplinas. 
Duhamel de Monceau, así como de los británicos Lisle y Home, el suizo Hirzel y los franceses Dupui-Demportes, Desplaces o Patullo, al igual que en el ámbito de la industria rural del tratado de Marcandier sobre la manufactura del cáńamo. El género alfabético sobre la economía doméstica y rural estaba representado por el Dictionnaire domestique de Roux.

El tercer grupo reseñaba obras de economía política propiamente dicha. La nueva tratadística francesa era prioritaria, especialmente las dos principales escuelas económicas de la Francia de su tiempo: la fisiocracia y, sobre todo, el grupo de Gournay, como fue general en Espańa. Los ecos fisiócratas en el periódico de Nifo se limitaban a los tratados de Mirabeau y Patullo (Nifo, 1763: n. X, 192 y ss.; n. XVIII, 279). En cambio, del círculo de Gournay aparecían reseñados volúmenes diversos y significativos. La serie la abrían las Considérations sur le commerce (1758), una profunda diatriba contraria a los gremios atribuida a Gournay y Cliquot de Blervache (ibid.: n. XIII, 199-200). A continuación, Remarques sur plusieurs branches de commerce et de navigation (1758) de O'Heguerty (ibid.: n. XXI, 321-322), encendida defensa del comercio. Por último, aparecía uno de los principales productos intelectuales elaborados por ese círculo: un conjunto de tratados y traducciones reunidos en seis volúmenes por Éléazar de Mauvillon bajo el título de Discours Politiques. El DE hacía mención a tres de los autores editados en esa obra colectiva: Hume, Bolingbroke y Cantillon. Resulta especialmente significativo que, por primera vez en Espańa, se identificara a este último como autor de los Ensayos sobre la naturaleza del comercio en general (ibid.: n. XXI, 321) ${ }^{7}$. Nifo captó el interés para su país de esas traducciones: «Francia puede aumentar su poder favoreciendo su agricultura y el comercio marítimo [...] si esto se dice de Francia, ¿qué no se podría decir de esta península?» (ibid.: n. XXI, 321).

Tal y como se ha indicado, en el sustrato de estas publicaciones se halla la propuesta de una política que hace protagonistas al comercio y, en general, a la actividad productiva, de manera que Nifo se alineaba con las élites ilustradas españolas que, especialmente a partir de los años sesenta, acogían con sumo interés la economía política, y a pesar de que, por su innovadora carga sociopolítica, carecía de una categoría disciplinaria propia. En los cuidados índices con los que, siguiendo los Annales, Nifo cerraba su DE, los textos de economía política aparecían dentro del epígrafe de "Jurisprudencia», junto a los que versaban sobre derecho natural y política.

7 El título en realidad es Ensayo, en singular. La obra había visto la luz en 1755 de forma anónima, y no sólo había comenzado a circular en España, sino que estaba llamada a conocer una notable fortuna en la Ilustración española (Astigarraga y Zabalza, 2007). 
La desaparición en agosto de 1763 del DE encontró sustitutos ese mismo año en el Nuevo Cordón Crítico General de España y la Aduana Crítica (en adelante, AC), si bien solo el segundo con contenido económico. Editado por José Miguel de Flores y la Barreda, trataba de hacerse un espacio en la crítica literaria denunciando los defectos de las publicaciones recientes ${ }^{8}$. En efecto, sus reseńas eran más extensas, bien informadas y de notable actualidad, pero sus inmersiones económicas, escasas. Además de volver a sintetizar diversos capítulos de Forbonnais (véase nota 7), reseñó el manual de comerciantes de Cantos Benítez (1763) y la traducción española del Ėloge (1763) de Sully por Thomas. Sobre esta segunda incidía en que la calidad de la versión española era «regular». De esta manera, la AC volvía a mostrar sin tapujos la deuda de la prensa espańola con la francesa. Su relevancia consistía en la exigencia de que la labor traductora fuera trasparente y correcta. En cualquier caso, su propósito de enmienda tuvo poco éxito. El periódico fue más efímero que el de Nifo: cerró en febrero de 1765, tras veintiséis números.

En abril de 1765 aparecía el Semanario Económico (en adelante SE, 1765-1767), de Juan Pedro Saura, bajo el acrónimo de Araus (Ocampo, 2013). Alejada de la crítica literaria, la cabecera estaba orientada a las artes aplicadas, con un perfil científico y utilitario que era muy visible en sus prolijas noticias sobre la economía rural. No obstante, la nueva agricultura ocupaba menos espacio que el de autores más clásicos como Chomel, una de las fuentes centrales de las noticias económicas de la publicación, o Alletz, así como diversas memorias de las sociedades agronómicas europeas.

El SE también incluyó noticias sobre política (Réal de Curban) y el «comercio». Las dedicadas a este segundo aparecían bajo la forma de comentarios de libros, que contenían normalmente valoraciones del editor. Esas noticias bebían de fuentes diversas, siempre francesas, como las Mémoires de Trévoux o el Journal des Savants; no obstante, las fundamentales fueron el Journal Oeconomique, ou Mémoires, notes et avis sur l'agriculture, les arts et tout ce qui peut avoir rapport à la santé ainsi qu'à l'augmentation des biens de famille (en adelante, JOE, 1751-1772) y el Journal de commerce (en adelante, JC,

8 A Clavijo le acusaba de presentar como originales artículos traducidos (Aduana Crítica, 1763, vol. I, p. 105). Así lo mostraba la traducción de los capítulos sobre la historia del comercio de los Élemens du commerce (1754) de Forbonnais, cuya calidad ya había sido discutida por Nifo (Astigarraga, 2014). Respecto al DE decía De la Barreda que trataba de "copiar o traducir» obras periódicas extranjeras, pero de forma defectuosa. Sus reseñas no transmitían una información correcta del libro reseñado, pues eran «diminutas», de «sustancia reducida» y con noticias «superficiales» (Aduana crítica, 1763: vol. II, 13-16). De la Barreda había contrastado el trabajo de Nifo con los originales franceses, a los que él mismo recurría para publicar sus reseñas. 
1759-1762); es decir, los dos primeros periódicos económicos de la historia de la prensa francesa (Steiner, 1996). En particular fue el segundo un periódico mensual editado en Bruselas por Jacques Accarias de Serionne, escritor francés exiliado en dicha capital, el que marcó la línea de información bibliográfica de Saura. El JC se hizo presente en el SE en agosto de 1765, en una nueva rúbrica de "Noticias literarias y de comercio». Allí se mencionaba el Diario de Comercio de Bruselas, en el que, según Saura, se exponían los principios de «un siglo que solo piensa en aprovecharse de todas las ventajas del comercio» (SE, 1765: vol. I, 227). Saura anunciaba su intención de introducir en números posteriores artículos de esta "excelente» obra. En efecto, dos meses después extractaba la «Introducción» de Serionne para el JC, en la que se defendía que la "política hace al comercio la basa de los estados». Saura lo presentaba como un periódico cuyo contenido alcanzaba no solo «la mecánica del comercio sino también su administración, de suerte que se puede contemplar como un manual de los comerciantes y código de legisladores» (ibid.: 228). De esta manera, a través de JC, y en menor medida de JOE, el Semanario Económico se erigió en un canal privilegiado de los debates económicos de la Francia de los años cincuenta. Junto a diversos manuales de comerciantes y sobre usos marítimos (Cleirac, Huet, Le Page du Pratz, etc.), Saura reseñó autores tan representativos de la emergente economía política europea como el propio Serionne, Mably, Coyer, Gee, Cliquot de Blervache o Hume (Astigarraga, 2018). A través de sus reseñas trasladó al público español algunos de los tópicos más característicos de esa ciencia, que se presentaba con un perfil diferenciado de la clásica oeconomie: la balanza de comercio como balanza de poder (Serionne), el doux commerce y la «nobleza comerciante» (Coyer), el desarrollo colonial al servicio de la metrópoli (Gee), la influencia del tipo de interés en el crecimiento económico (Blervache), la relatividad de las costumbres y leyes (Hume) o el ambicioso proyecto de elaborar un «sistema fijo de política» (Mably). La secuencia de autores pone de relieve que Saura se alineaba con Gournay y su círculo de economistas, así como la voluntad de propagar una nueva propuesta sociopolítica que hacía de la economía política su punta de lanza.

\section{LA SEGUNDA ÉPOCA DORADA DE LA PRENSA ESPAÑOLA: EL MEMORIAL LITERARIO}

Hubo que esperar al florecimiento de la prensa española en su etapa dorada y madura, entre 1781 y 1808 , para que surgieran nuevas cabeceras sobre información bibliográfica. Esta fase se benefició del contexto más propicio para la prensa (Guinard, 1973: 219-220). Factores como la mejora de la difusión, debida al avance en las técnicas de edición y a la reducción de 
los gastos postales, la campaña en defensa de la libertad de imprenta (Foronda, Arroyal, Cabarrús, etc.), la atenuación de la censura (Velasco, 2000), o el impulso desde el poder, propiciaron la Orden de 19 de mayo de 1785 de Floridablanca, la primera ley favorable a la prensa del siglo xviı español (Larriba, 2012: 19-41; Urzainqui, 2012). No obstante, esta etapa dorada tuvo altibajos. Así, el 24 de febrero de 1791 Floridablanca decretó la supresión de todos los periódicos, salvo la Gaceta, el Mercurio y el Diario de Madrid, para evitar el contagio con la Francia revolucionaria (Domergue, 1981: 69-138; 1982: 147-192); pero Aranda revocó discretamente en 1792 esta decisión y la prensa vivió una nueva fase de esplendor (Urzainqui, 2009). De esta forma, el género de las reseñas de textos económicos adquirió su madurez, eso sí, a través de perfiles diversos. Uno de los periódicos más destacados de los años ochenta, el Correo de los Ciegos (luego de Madrid) —en adelante, CM, 17861791 - se convirtió en un simple altavoz para la transmisión de las sucintas novedades bibliográficas recomendadas en la Gaceta de Madrid.

El caso del Memorial Literario (en adelante, ML, 1784-1808) fue diferente. La cabecera fundada en 1784 por Joaquín Ezquerra y Pedro Pablo Trullenc, la de vida más dilatada de la Ilustración española, fue decisiva en la creación del género de las reseñas económicas (Guinard, 1973: 252-265; Urzainqui, 1992; 1990). La divulgación bibliográfica fue una de las fuerzas motrices del ML, publicación pionera en ese ámbito. Todos sus números contenían reseñas bibliográficas, agrupadas en una sección con tres rúbricas: libros impresos, reimpresos y traducciones. Esa sección se diferenciaba de la dedicada a «Memorias literarias extranjeras». Las reseñas respondían a criterios bibliográficos rigurosos y fueron cuidadosamente planificadas. En sus primeros ańos versaron solo sobre libros anunciados previamente en la Gaceta de Madrid, muestra del carácter semioficial del ML. No eran mayoritariamente traducciones copiadas de revistas extranjeras, sino que fueron elaboradas en el ML, siguiendo criterios homogéneos. Todo ello es aplicable sin excepción a los textos sobre economía política. Dejando a un lado algún precedente aislado, en el ML aparecieron las primeras reseńas de esta disciplina en la historia de España. Estas incluían las publicaciones nacionales, las traducciones y, excepcionalmente, textos inéditos en Espańa. Todo apunta a que todo se debió a la labor personal de Ezquerra, cuya mano académica y su buena formación humanística son patentes. De hecho, la sección de crítica de libros se mantuvo estable durante la etapa en que él se mantuvo al frente del ML, hasta enero de 1805, y bajó significativamente cuando esta pasó a manos de otros editores, los hermanos José María y Mariano Carnerero (Cavaillon, 2019: 357).

Con el fin de reforzar el impacto de las reseñas del ML, Ezquerra publicó durante 1784-1791 la Biblioteca periódica anual para utilidad de los libreros y 
literatos (Madrid, Imprenta Real, 1784-1791, 2 vols.), un catálogo de las novedades bibliográficas anuales, muchas de ellas reseñadas ya en el ML. Su objetivo era solventar la falta en España de índices de las obras publicadas para que estas se extendieran "con más facilidad» y llegaran a públicos diferentes que ese lector interesado en las novedades culturales al que se dirigía el ML. En efecto, los principales destinatarios de la Biblioteca eran los literatos y, sobre todo, los comerciantes de libros (Biblioteca, 1785: vol. I, n. II, Advertencia, sin paginar).

La serie completa de reseñas publicada en el ML representa un listado muy significativo de los textos y las traducciones económicas que vieron la luz en las dos últimas décadas del siglo xviII. En su primera época (1784-1791), aparecieron reseñados en sus páginas los escritos económicos de Aguirre, Arteta, Álvarez Enciso, Campillo, Cornide, Foronda (tres reseñas), Elies y Rubert, Loynaz, Marien Arróspide, Nifo, Pérez y López, Sempere, Torre Mollinedo, Zavala y Ward. También fueron habituales las reseñas de contenido agronómico y naturalista (Bowles, Castellnou, García de la Huerta, Maurueza, Navarro y Más, Salvá y Campillo, Valcárcel, Vallemont, etc.), de las memorias de las sociedades económicas (Matritense, Vascongada, tudelana, etc.) y sobre aritmética comercial (Bails, Herranz, etc.). La cuidadosa planificación del editor se muestra en el tratamiento que recibieron obras enciclopédicas de publicación periódica, como las Memorias (1778-1791) de Suárez y Núñez, la Agricultura General (1765-1795) de Valcárcel o las Memorias (1787-1800) de Larruga, cuyos volúmenes eran reseñados a medida que veían la luz.

Un indicador aún más preciso de la calidad del ML procede del tratamiento de los textos extranjeros. Solo excepcionalmente figuraron algunos textos inéditos en España, como las Observations sur le gouvernement et les loix des États-Unis d'Amérique (1784) de Mably y la Scienza della legislazione (1780-1791) de Filangieri, antes de que fuera traducido. En cambio, el periódico está jalonado de una serie muy representativa de las traducciones económicas publicadas en España. Los autores reseñados fueron: Belloni, Beguillet, Bielfeld, Carli, Donato, Dupont de Nemours, Forbonnais, Genovesi, Filangieri, Hume, La Forest, Mably, Muratori, Necker, Raynal, Rozier y Toaldo (referencias concretas de las traducciones, en Llombart, 2004). El tratamiento en forma de cuidadas reseñas sucesivas que recibieron las traducciones enciclopédicas de Linneo, Rozier o Buffon a medida que iban viendo la luz sus respectivos volúmenes, y que se extendieron en algunos casos hasta la última etapa del ML, incide en la calidad de este. Las reseñas ayudan a interpretar la intensidad de la recepción en España de la literatura extranjera. Algunas no fueron de traducciones coetáneas, pero sirvieron para recordar autores especialmente influyentes (Forbonnais). Otros fueron objeto de más de una reseña. 
Esto sucedió con Bielfeld (2), Belloni (2), Necker (3), Genovesi (3) y, sobre todo, Filangieri (8), lo cual refleja la importancia que se atribuyó a su obra en plena eclosión del debate constitucional en España (Astigarraga, 2005a). En otros casos, las reseńas recomendaban la obra debido a la calidad de la traducción española: así, las abundantes notas críticas introducidas por Villava a su versión de Genovesi estaban «manejadas con destreza y buen método», mientras que la utilidad de la traducción parcial y censurada de la polémica obra de Raynal realizada por el duque de Almodóvar aumentaba una vez suprimidos todos sus «desbarros».

En la segunda época del ML (1993-1801), la sección de reseñas conoció, al igual que toda la publicación, una cierta pérdida de dinamismo y actualidad. El declive se había iniciado a finales de 1790, cuando, tras la muerte de Trullenc, Ezquerra pasó a ser el artífice único del periódico, con la posible colaboración del santanderino José Calderón de la Barca. A pesar de ello, la sección de reseñas mantuvo sus criterios. Diversas obras enciclopédicas, como las de Larruga, Buffon o Valcárcel, continuaron siendo reseñadas. También se dio inicio a las de otras obras de características similares, como las Observaciones (1995-1997) de Cavanilles y las Lecciones prácticas de agricultura (17921795) de Vicente Seixo. En cuanto a los libros españoles, además de las memorias de las sociedades económicas, de textos sobre derecho natural (Molloy) y la economía agraria (Dieste y Buil, Carballo, etc.), se informó de los tratados de Alonso Ortiz, Antúnez y Acevedo, Campillo, Foronda, Ibarrondo, Matanegui, Marín, Martínez de Mata, Paula del Rey y, por último, Pérez y López.

En el ámbito de las traducciones, figuraron obras fronterizas —el ejemplo más significativo fue de De l'origine des lois, des arts et des sciences (1759) de Goguet- y sobre agronomía: en noviembre de 1797 el ML comenzó a informar de una de las traducciones centrales de la Ilustración española: el Cours complet d'agriculture (1781-1800) de Rozier. Sobre economía política fueron reseñadas las versiones de Accarias de Serionne, Coyer, Huet, Herbert, Risteau, Lampredi, Muratori y Smith. Tres de ellas merecen una mención particular. La de Herbert, debido a que el ML destacaba las observaciones críticas que había introducido su traductor, el aragonés Anzano (Astigarraga-Usoz, 2009). La de Accarias de Serionne, debido a que la reseña fue publicada con una veintena de años respecto de la traducción española; no obstante, con el telón de fondo de las guerras napoleónicas, la defensa que en la obra se realizaba del «espíritu del comercio» la convertía en actual: «El problema es haber ido a la guerra en vez de dirigir la política al comercio" (ML, 1794: XII, I, 423). Por último, el ML no solo dedicó dos reseñas a la obra de Smith, sino que fue un verdadero altavoz de la importancia de la traducción de Alonso Ortiz: antes de describir con detalle su contenido, se destacaban las repetidas 
versiones europeas que se habían realizado de la obra en un corto espacio de tiempo.

Es perceptible el languidecer gradual de este género en el ML con el paso de los años: durante los siete años de la primera etapa (1784-1791) fueron publicadas una veintena de reseñas de autores españoles y una treintena de traducciones, mientras que durante los cinco años de la segunda etapa (17931997), en conjunto, apenas sumaron la veintena. A su vez, las reseñas habían crecido gradualmente hasta alcanzar el pico de ocho reseñas de textos traducidos en 1789, y decayeron a partir de entonces hasta 1797, el primer ańo en que no apareció ninguna de libros traducidos. Todo ello no era sino el preludio de la desaparición virtual de ese género, que se consumará en la tercera etapa (1801-1808). Entonces solo fueron publicadas de manera testimonial (Foronda y Sempere). Tan solo las sucesivas reseńas del enciclopédico Cours de Rozier quedaron como testimonio de un género que había florecido de la mano de Ezquerra.

Una mirada conjunta permite comprender mejor el sentido de las reseñas del ML. En primer lugar, estas no fueron seleccionadas por un criterio doctrinal: su campo ideológico fue tan plural como lo fue la economía política española de finales del siglo XvıII. También resulta muy informativa su composición. Las reseñas eran básicamente de dos tipos: las que ofrecían un breve resumen del contenido de la obra y las que describían su estructura interna. En ambos casos, eran más informativas que valorativas. La genuina labor de crítica que se atribuye a las reseñas aparecía tan desdibujada que era imperceptible: no hay una sola reseńa negativa de textos de economía política en todo el ML. En este mismo sentido, no es un dato menor que se ciñeran a libros ya publicitados en la Gaceta de Madrid. Esta exagerada prudencia llegó a desatar los reproches de los lectores hacia los redactores (Guinard, La presse, pp. 256-258). Sin embargo, el ML no alteró su orientación. El objetivo último de sus reseñas era informar al público para inclinarle positivamente hacia el libro e instigar su lectura. Ajenas pues al ejercicio de la crítica, aquellas emergían como un instrumento de apoyo a la propaganda ilustrada en favor de la difusión de aquellos libros considerados útiles desde la perspectiva de la maquinaria oficial.

\section{LOS PERIÓDICOS RECOPILADORES: EL ESPÍRITU DE LOS MEJORES DIARIOS}

En su estudio clásico sobre la prensa francesa, Eugène Hatin resaltó la existencia de un tipo de periódicos «reproductores». Su finalidad era compilar las novedades bibliográficas publicadas en otras revistas, francesas o 
extranjeras, con el fin de multiplicar el impacto de esas novedades entre el público (Hatin, 1859-1861: vol. III, 197 y ss.). Este tipo de periódicos fue adquiriendo una notable función social a medida que la hidra periodística crecía en volumen y especialización y, debido a ello, sus lectores encontraban dificultades, no solo de índole financiera, para mantenerse al día. Por ello, es lógico que en el caso de España alcanzaran su madurez durante la etapa dorada de la prensa. De hecho, la primera iniciativa se publicó en mayo de 1781 bajo el título del Correo Literario de la Europa (CLE, 1781-1782; 1786-1787). Es muy probable que Nifo se hallara detrás de la misma, pues fueron dos cercanos familiares suyos, su yerno Francisco Escartín y su hermano Joaquín, quienes desde París y Madrid, respectivamente, la pusieron en marcha. El semanario fue efímero. Aparecieron 86 números, recopilados en dos volúmenes entre 1781 y 1782, y contó con un breve resurgir en otro tercer volumen, de octubre de 1786 a enero de 1787. Su fin era indagar en la diversidad europea de leyes y costumbres, para que España pudiera disponer en dos o tres décadas de un "perfecto sistema de legislación propia» (CLE, 1781: vol. I, n. I, «Advertencia al lector»). A ello se apelaba con sentido de autoridad, a pesar de su evidente disparidad metodológica, bien remarcada por los editores, a las obras de Montesquieu y Mably. Para cumplir ese objetivo, el periódico informaba sobre la actividad de las academias e instituciones europeas, invenciones de artes y oficios y noticias sobre el comercio europeo. No obstante, su espacio mayoritario lo ocupaban las reseñas de libros extranjeros que, desde el número 35, se ampliaron a los españoles. Subproducto de la prensa francesa de ese tiempo, con toda probabilidad de l'Esprit des journaux, la economía política ocupaba en sus páginas un espacio marginal y carecía de una rúbrica específica — se insertaba en las de jurisprudencia y política-. Hubo reseñas sobre obras menores (Loch) y sobre tratados de policía y política (como los de Robinet o Desessarts). Solo dos grandes nombres se abrían paso en su contenido. El primero era Filangieri (tres reseńas), cuya Scienza della legislazione se presentaba como «la maestra de la Europa en todo género de ciencias» y adecuada para abogados o gestores de la educación. El segundo era Necker, de quien se destacaba su trayectoria en la Hacienda francesa y se elogiaba su Compte-rendu: el «hacer pública la administración» era el fundamento de la «confianza pública» (ibid.: n. 15, 215-216).

El Espiritu de los Mejores Diarios Literarios que se Publican en Europa (EMD, 1787-1791), editado por el mallorquín Cristóbal Cladera, fue el más relevante de los periódicos compiladores españoles. Aparecieron 272 números, de julio de 1787 a febrero de 1791, primero cada tres semanas, y a partir de mayo de 1788 semanalmente (sobre EMD y Cladera, Sempere, 1785-1789; Sáiz, 1983; Urzainqui, 1995; Larriba, 2013; sobre el contenido del EMD, Guinard, 1973: 265-272 y Elorza, 1970: 119-138; dos índices del EMD, Hüttner, 
2009 y Varela Hervías, 1966). Su fundación, en julio de 1787, pudo estar instigada desde la Academia de la Historia. En 1787, Cladera había intentado que le fuera aprobada una revista titulada Biblioteca Periódica y Elemental de Ciencias, Artes, Literatura. En el informe censor de la Academia de la Historia, contrario al proyecto, se defendía la utilidad de un «diario de las obras que salen dentro y fuera de España» (Varela, 1966: 65). Esta fue la función principal del EMD. Esta no fue una publicación especializada, sino cultural en su sentido más amplio. Estaba destinada a las élites letradas, interesadas en la actualidad de las ideas y las novedades bibliográficas. Incluía, si bien en un espacio reducido, informaciones sobre legislación, instituciones oficiales (el Banco de San Carlos o la Junta de Comercio) y sobre las sociedades ilustradas españolas y europeas (discursos o premios). Tampoco eludió los debates cruzados ni las contribuciones de sus colaboradores, entre los que figuraron autores de la talla de Foronda o Ugartiria. No obstante, su leiv motiv fue la publicación de reseñas e informaciones bibliográficas. El EMD era un "periódico de periódicos». Trataba de capturar el «espíritu» de diversos diarios europeos para difundir "con la mayor exactitud e imparcialidad todas las novedades curiosas o importantes» (EMD, 1787: n. I: «Idea de la obra»). Y lo hizo con un éxito indiscutible. Disfrutó de tiradas poco habituales para su tiempo (rondaban los 1400 ejemplares). Entre sus suscriptores se hallaron los principales ilustrados de su tiempo, incluido Floridablanca, secretario de Estado, quien pudo tutelar la iniciativa de Cladera (Hüttner, 2009: XI). Además, no solo circuló en la Corte, sino también en provincias y en el ultramar hispano (Larriba, 2013: 88-89).

Por medio de la divulgación de la actualidad bibliográfica, el EMD se convirtió en altavoz, cosmopolita y paneuropeo, de la actividad intelectual de las luces europeas durante el fértil período que transcurrió entre el nacimiento de los Estados Unidos y la Revolución francesa. La lucha contra la intolerancia religiosa, el despotismo o los monopolios económicos, y la defensa del humanismo penalista o el pacifismo, fueron temas habituales en el periódico. También lo fueron, con una naturaleza pionera en la Ilustración española, las posiciones antiesclavistas o la defensa de los nuevos derechos del hombre. Así pues, como sucedió con la prensa europea de ese momento (Chartier, 1995:180-181), el periódico fue un instrumento indiscutible de la politización de la esfera pública española y en el que mejor se percibe la instigadora contribución de la economía política a la naciente formación de la opinión pública (Usoz, 2015: 105-127; Fernández Sebastián, 2015: 203-233). A pesar de ello, operó también con líneas rojas. Las cuestiones religiosa o colonial fueron abordadas con celo y equilibrando las posiciones extremas, más aún después de que debido a las arriesgadas opiniones de uno de sus colaboradores sobre las colonias españolas perdió temporalmente el permiso de edición. 
Las reseñas bibliográficas del EMD no fueron originales, sino una mera traducción de otras extraídas de diversos periódicos extranjeros. A diferencia de lo que se considera normalmente, sus fuentes fueron en realidad muy reducidas. Su modelo fue el L'esprit des journaux français et étrangers (EDJ, 1772-1818), la exitosa cabecera mensual especializada en novedades bibliográficas y editada en Lieja por Jean-Louis Coster y Jean-Jacques Tutot (Guinard, 1973: 265; Hüttner, 2009: XI). A ella se sumaron otras dos: los Annales politiques, civiles et littéraires du Dix-huitième Siècle (APC, 17771792) del abogado y polémico periodista Simon-Nicholas-Henri Linguet, y el Journal encyclopedique (JEC, 1755-1794). Este segundo era, como el EMD, un digesto de la prensa internacional. Bimensual, fue editado en Lieja por el empresario cultural Pierre Rousseau con la ayuda de otras firmas prestigiosas (Brissot, Panckoucke, etc.). Así pues, el EDJ y el JEC ejercieron como auténticos mediadores respecto de los periódicos italianos (el Giornale enciclopedico de Vicenza o las Novelle letterarie de Florencia), británicos (Monthly Review and British Register, Britsh Magazine o Critical Review), flamencos, holandeses, alemanes y portugueses que Cladera aseguró utilizar para componer su periódico (EMD, 1788: n. 124, 64). La identificación detallada de las fuentes de sus reseñas delata la influencia vertebral del EDJ, periódico «voleur y compilateur» (Hatin, 1859-1861: vol. III, 197). Por otra parte, de las 65 reseñas económicas del EMD no se conoce la procedencia de un $20 \%$; en cuanto al resto, el EDJ acapara más del $60 \%$ y el JEN el $25 \%$, mientras que las restantes se las repartieron el JEC y el JS.

Tres rasgos singularizaron las reseñas del EMD respecto a las publicadas por el coetáneo ML: versaban casi exclusivamente sobre textos foráneos - el EMD solo reseñó a cuatro especialistas sobre economía política hispanos: Campomanes, Sempere, el duque de Almodóvar y Clavijero-; eran normalmente extensas y adoptaban el perfil de auténticos book reviews; y, por último, incorporaban la crítica. Este último aspecto era muy sustancial. La crítica era entendida más allá de las habituales defensas apologéticas del honor nacional, la cultura española o de la necesidad de conformar los textos a criterios literarios correctos, para orientarse hacia un ejercicio de valoración de las obras reseñadas (Urzainqui, 2000: 519-559). Por tanto, el EMD trataba de crear un lector no solo instruido, sino también crítico. De hecho, no siempre reseñaba libros valorados positivamente y, además, introducía comentarios del editor sobre el aspecto formal o el contenido de la obra. En manos de Cladera la reseña se convirtió así en un instrumento con poderosas funciones socioculturales, informativas y de conformación de la opinión pública. La reseña suponía una vía de lectura rápida y menos costosa y multiplicaba el impacto del libro elegido entre el gran público. La copia habitual de párrafos textuales del mismo la convertía en una manera sutil de 
introducción del pensamiento foráneo. Además, ayudaba a salvar los límites de la censura. El libro de Raynal, traducido parcialmente y con muchas censuras en España, fue objeto de reseñas extensas del original francés. El dedicado por Necker a la cuestión religiosa, que había sido intentado traducir sin éxito en España debido a su complacencia con el protestantismo, fue reseñado en el EMD con el intento de disponer «el ánimo del lector en favor de esta obra» (EMD, 1788: n. 123, 51).

La economía política ocupó ya desde los primeros números del EMD un espacio muy relevante. En los casi cuatro ańos en que se mantuvo vivo, publicó más de seis decenas de comentarios bibliográficos con ese contenido. La disciplina apareció subsumida en dos rúbricas, una de "literatura y comercio» y otra de "ciencias y artes", creadas en abril de 1788. A partir de enero de 1791, siguiendo el modelo adoptado por el EDJ a partir de 1775, esta segunda fue sustituida por otra sobre «literatura, comercio, agricultura y economía política». Al tratarse de un periódico cultural y no especializado, tampoco lo fue su contenido económico, que fue plural. En el EMD estuvieron representadas las principales corrientes de la economía política europea: la fisiocracia, a través Mirabeau y Dupont de Nemours; el círculo de Gournay, por Forbonnais; o la economía clásica: la reseña de la Wealth of Nations de Smith, muy elogiosa, aludía a su traducción francesa, publicada en 1790, cuatro años antes que la española de Alonso Ortiz.

Asimismo, a pesar de su deuda con fuentes francesas, las reseñas económicas del EMD se alimentaron de la pluralidad geográfica. Sobre la Ilustración escocesa se publicaron extensas notas de Smith, Millar, Priestley y Sinclair. El periódico fue también el principal transmisor en la Ilustración española de las novedades publicadas en Italia, en particular en el Nápoles borbónico, tanto en la vertiente económica como la jurídica. La primera estuvo representada por auténticos pesos pesados de la Ilustración napolitana, como Filangieri, Galanti o Delfico; la segunda por autores como Giustiniani, Mattei o Pagano. La Scienza della legislazione de Filangieri, con la que se abría el primer número del periódico, ocupó un lugar sobresaliente en él. En 1787 se subrayaba que el napolitano abrazaba mejor que Montesquieu «el verdadero camino de la filosofía». Dos años después, en plena eclosión de la llegada de la Scienza a España, se describía su obra "como un sistema completo y raciocinado que abraza todos los ramos de la legislación» (EMD, 1787: n. 1, 12; 1789: n. 186, 169-178).

Un rasgo característico del EMD fue la estrecha vinculación que la economía política presentó en sus páginas con obras de orientación estrictamente política. Ello era un reflejo de que fue publicado en un momento en que se hacía particularmente evidente la importancia de la economía política en el naciente debate constitucional (Astigarraga, 2005a, 2005b). También en 
este terreno dominó la pluralidad ideológica. En el EMD se presentaron argumentaciones enraizadas en el conservadurismo católico, en favor de la monarquía absoluta (Ferrieres) o contrarias a las posiciones políticas de Rousseau o los fisiócratas (François). Pero junto a ello se ofrecieron reseńas de las obras de Brissot de Warville o De Lolme, nucleares en la construcción del primer constitucionalismo español. También adquirió una relevancia notable la evaluación del modelo político británico. Sobre este tema la reseña más significativa fue la elogiosa dedicada a la historia Why, muy influenciada por Hume y Smith, del escocés Millar. Algo similar ocurrió con la creación de la república de los Estados Unidos. Sobre este tema trató particularmente la extensa reseña del libro del florentino Mazzei, colaborador de Jefferson, publicado con cuatro cartas de Condorcet sobre la unidad de la legislación y muy crítica con Raynal y Mably. La reseña destilaba simpatía hacia los principios de la nueva república: libertad económica y lucha contra los monopolios o el tráfico de esclavos.

Más allá de cualquier afán de erudición, la selección de las reseñas extranjeras realizada por Cladera cumplía también una finalidad eminentemente política: se trataba de conformar una opinión pública favorable a las reformas borbónicas. Es claro que Cladera eligió diversas reseńas para dar cobertura a las reformas fiscales coetáneas del ministro Lerena, como su política de transparencia presupuestaria —el EMD publicó los primeros presupuestos públicos de la prensa española - o su estímulo a la realización de una investigación sistemática sobre la Hacienda espańola. La defensa de la orientación arancelaria proteccionista, adoptada en el arancel decretado en 1782 por su antecesor Múzquiz, suscitó reseñas de autores como Cliquot de Blervache o Serre de la Tour. El trasfondo político resulta también indiscutible en la amplia atención que el EMD prestó al tema de la deuda pública: desde inicios de los años ochenta, la Hacienda española padecía déficits crecientes. Las críticas al recurso indiscriminado al endeudamiento fueron abordadas a través de las obras del francés Lesperat y los británicos Sinclair, Playfair y Priestley.

El EMD reflejó muy bien el impacto que la cuestión agrícola tuvo en la Ilustración española y europea, tanto en el plano teórico como el aplicado. En él dejaron una profunda huella la multiplicación de tratados y revistas especializadas acerca de esa cuestión. En el periódico vieron la luz memorias y experiencias agrícolas procedentes de sociedades francesas, italianas (Milán, Vicenza, Turín) o portuguesas (Lisboa), así como otras noticias provenientes de Alemania o Gran Bretańa. También fue muy visible la literatura agronómica de formato enciclopédico, debida a Rozier o a otro agrónomo francés, Sutières-Sarcey, así como los comentarios de libros de otros nombres insignes de la agronomía europea como Fabroni, Tessier, Parmentier, Vandelli o Arthur Young. La divulgación agronómica realizada a través del EMD se incardinaba 
en la «nueva agricultura», caracterizada por la lucha contra los usos agrarios seculares y la aplicación a la agricultura de los saberes de ramas afines (botánica, química, etc.). El anhelo experimental que recorría la Europa de la segunda mitad del siglo XVIII se trasladó de forma impetuosa al EMD en todas las ramas de la economía rural, ya fuera el cultivo de los granos, la extensión de los prados artificiales o la divulgación del nuevo utillaje agrícola. Las numerosas informaciones que el periódico publicó sobre estas cuestiones poseían un indiscutible afán de popularizar los conocimientos y las técnicas agrícolas y se complementaban bien con el que venían realizando desde 1775 las sociedades económicas españolas.

Esta defensa de la agricultura no fue óbice para que el EMD abordara la cuestión del comercio. Diversas tipologías de textos encararon esta cuestión partiendo de una óptica plural. En un caso, las reseñas mostraban las bondades del comercio (Bertholon). En otro, introducían una narrativa favorable a él desde posiciones católicas, resaltando que sus ventajas sobre el bienestar y la dulcificación de las costumbres superaban con creces los inconvenientes en términos de devaluación de la virtud cívica (Baudisson). No obstante, en el EMD también se divulgó la vieja visión republicana contraria a las riquezas y al lujo, debido a que destruían la igualdad y el orden social (Meilhac), o la reflexión sobre las alteraciones que la sociedad del comercio generaba en las relaciones de la moral con la política (Dahblerg). Ahora bien, junto al comercio, nada refleja mejor los difíciles equilibrios internos que exigía a Cladera mantener vivo su periódico que el tratamiento del estatus económico del clero. A un lado, figuraron en él defensas de su condición privilegiada y del derecho al cobro de los diezmos (Herve); al otro, críticas encendidas de sus abusos, debido a que acumulaba riquezas y se entrometía en la vida política y civil (Rozet). Como un último elemento del EMD, ahora realmente innovador, figuraba su posición abolicionista respecto al tráfico de esclavos. Sobre ella incidía la experiencia constitucional de los Estados Unidos, pero también otras numerosas reseñas de formatos diversos, desde las reflexiones filosóficas a la narrativa de viajes. Entre todas ellas destacaba la avanzada obra de Condorcet. Así pues, siempre con el telón de fondo del EDJ o el JEC, y mucho más allá de lo que hasta ahora se ha considerado, Cladera fue esencialmente un traductor. Su labor esencial como editor del EMD consistió en seleccionar y verter al español productos intelectuales que difundieran en España la intensa actividad de las luces europeas y resultaran útiles desde la óptica de los problemas que encaraba la Monarquía.

El EMD fue clausurado en febrero de 1791, una vez publicados 272 números. El motivo fue la mencionada resolución de Floridablanca de 1791, que cerró la prensa ilustrada para evitar el contagio con los aires revolucionarios procedentes de Francia. El espacio de los periódicos compiladores lo 
ocupó entonces la Miscelánea Instructiva, Curiosa y Agradable (MI). Obra de tres editores, Diego María Gallard y los hermanos Francisco y Matías Pinilla, publicó veinticinco números en cinco años (1796-1800). Concebida inicialmente como una recopilación de ensayos sobre historia, elocuencia y educación, así como de piezas literarias, a partir de su décimo número (1797) se especializó en informaciones bibliográficas. Se perfiló entonces como unos «anales de literatura, ciencias y artes sacados de los mejores escritos que se publican en Europa", que combinaban reseñas extensas con referencias bibliográficas breves. Aunque luego no fueran respetadas, una de sus ocho rúbricas versaba sobre «fábricas y comercio».

La MI era una auténtica miscelánea de temas diversos, que incluía además "cosas curiosas», dado que su objeto no era solo la instrucción, sino multiplicar los lectores de la prensa (n. I, «Advertencia al lector»). Aunque fuera uno de los primeros periódicos españoles en publicar sistemáticamente extractos de revistas coloniales (principalmente de Perú, La Habana y Guatemala), su contenido esencial procedía de los digestos recopiladores en lengua francesa. A los dos más habituales, el EMD y el JEC, se unía ahora el Magasin encyclopédique (1792-1816). De ellos procedían las reseñas sobre economía política. Sobre esta el periódico advertía de que se trataba de una ciencia en formación, "casi nueva», todavía no «reducida a un corto número de principios sencillos e incontestables» (MI, 1797: vol. IV, n. XI, 240). Quizás debido a ello, ofreció informaciones bibliográficas de autores tan dispares como Forbonnais, Smith, Mirabeau, Say, Bentham, Garnier, Condillac o Guiraudet. Asimismo, sus enfoques fueron muy diversos. La geografía económica y la cuestión colonial se presentaban entrelazadas con tratados sobre policía municipal (Saint-Aubin y Colquhoum) o economía social (acerca de la beneficencia y las cárceles). Por último, fue el primer periódico español en dar inicio a la difusión de los escritos del Conde de Rumford y Arthur Young, que disfrutarán de gran fortuna en España.

El MI publicó noticias sobre economía rural (Rougier de la Bergerie, Campo, etc.) y manuales de comerciantes (La Barthe, etc.), pero su auténtica especialización fueron las artes industriales. Fue un firme defensor de la maquinización, las invenciones en la industria y de la aplicación a ella de los descubrimientos científicos de la física y química. El periódico pivotaba alrededor de un liberalismo no doctrinario que se oponía a los gremios, pero defendía las funciones de la inspección de la calidad, los reglamentos industriales y, bajo determinadas premisas, los privilegios exclusivos. Su alejamiento del pensamiento smithiano es perceptible en diversos enfoques, como la cuestión impositiva. La razón puede hallarse en que fue el primer periódico español en conectar con las propuestas económicas que irradiaban desde las nuevas instituciones parisinas del Institut National y el Conservatoire des arts et métiers. 


\section{LA ECONOMÍA POLÍTICA EN LA PRENSA CIENTÍFICA: LAS VARIEDADES DE CIENCIA, LITERATURA Y ARTES}

Las Variedades de Ciencia, Literatura y Artes (1803-1805, 48 números) tuvieron la finalidad de "propagar los diversos descubrimientos que se verifican en los conocimientos humanos con más prontitud que se logra por medio de los libros» (1804: año I, Prospecto, vol. I, n. I, 4). En efecto, sus fundadores veían en la prensa el medio más rápido y barato para ello, más aún cuando, como ellos subrayaban, los periódicos extranjeros proliferaban sin cesar y resultaba cada vez más oneroso y difícil mantenerse al día. Bajo la apariencia de un periódico compilador, fue sin embargo algo más que ello. El periódico aspiraba a difundir «las novedades literarias más interesantes, así nacionales como extranjeras»; por ello, reunía un conjunto muy variado de contribuciones, esencialmente memorias, discursos y reseñas, Aunque publicó artículos de colaboradores externos y aparecieron debates cruzados entre sus lectores, su contenido sustancial fue debido a los siete miembros del equipo de redacción inicial. Entre ellos figuraron literatos y científicos eminentes, como Manuel José Quintana o Juan Álvarez Guerra. A ellos se unieron posteriormente otros destacados hombres de ciencias, como Proust o Antillón.

Las matemáticas, la física, la química y las ciencias naturales ocuparon el eje central de las Variedades, sazonado con artículos sobre bellas artes y literatura. Fue el primer periódico español que contribuyó a la difusión de los idéologues franceses. De hecho, una parte notable de sus contenidos científicos provenían de las publicaciones del Institut Nationale de París. Junto a ello, Desttut de Tracy y Condillac contaron con sendas reseñas. Ambas aludían a sus respectivas traducciones espańolas. En la del segundo, se elogiaba tanto la obra como la calidad de su versión española, debida a la marquesa de la Espeja.

En cuanto a su contenido económico, quedó limitado a la agricultura y la economía rural, materias integradas en la rúbrica del periódico sobre medicina y artes industriales. Sus contenidos fueron obra del ilustrado extremeño Juan Álvarez Guerra, quien figuró entre los fundadores del periódico, pero su vinculación fue más intensa en 1805 , su último año. La especialización agrícola de las Variedades la convierten en una excepción en la prensa española, junto al mencionado Semanario de Agricultura, en el que también colaboró Álvarez Guerra.

Juan Álvarez Guerra fue un extraordinario divulgador sobre cuestiones agrícolas. Cuando se vinculó al periódico acababa de finalizar la traducción del Cours (1781-1800) del Abbé Rozier. Publicada entre 1797 y 1803, fue uno de los key works del pensamiento agrario ilustrado español. Al mismo tiempo, en ese momento había emprendido, junto con otros colaboradores, la traducción del nuevo Dictionnaire (Paris, 1803) sobre historia natural 
aplicado a las artes y la economía rural elaborado en el Institut Nationale (1804: año I, n. I, 44). Según afirmaba, esa traducción se hallaba muy avanzada y contaba con el apoyo real para su impresión. Aunque también firmó algunos artículos sobre ciencias puras e historia eclesiástica, fue esta misma labor de divulgación especializada en economía rural la que desarrolló en las Variedades?.

Álvarez Guerra entendía que el progreso de la agricultura dependía del desarrollo de la botánica, la química, la mineralogía y otras ciencias auxiliares. De ahí su énfasis en la educación. Esbozó un plan de formación en esas ciencias, que se inició en las escuelas de primeras letras y culminó en las instituciones científicas de la corte. No obstante, su empeño principal era simplificar los conocimientos agronómicos para que pudieran ser comprensibles entre los labradores. Y lo mismo ocurría con las artes industriales. Su preferencia era un modelo cercano a la industria rural popular, como el curtimiento de cuero, al que dedicaba una de sus instrucciones. Se debían fomentar las artes más sencillas, pues exigían menos formación de capitales y operarios, y eran al mismo tiempo de consumo más general (ibid.: n. IV, 212-226). Por todos estos motivos, Álvarez Guerra ensalzaba la labor divulgativa realizada por las sociedades económicas a través de la difusión de tratados y premios, y reclamaba la creación de escuelas de agricultura. Toda esa labor se relacionaba con su pretensión de elaborar unos "Elementos de agricultura", que habrían de comprender tres partes: agricultura teórica, práctica y económica (ibid.: n. III, 151-159).

Por su parte, con sus reseñas trataba de solventar la escasez de libros y de lectores sobre agricultura. Entendía que con ellas se formaría una masa crítica de lectores que podría intervenir en la arena política a través de la opinión pública: pretendía, en suma, hacer «crecer el número de personas suficientes para fijar la opinión pública» (ibid.: n. IV, 222). Algunas de sus reseñas fueron de factura propia y actuaban como altavoz de los tratados científicos publicados por el grupo de agrónomos más prestigioso relacionado, como él mismo, con la Sociedad Matritense y el Jardín Botánico: los hermanos Claudio y Esteban Boutelou y Casimiro Ortega. Otras adoptaban la forma de discursos de factura propia. Por fin, existieron extractos que, a modo de reseñas, tradujo de los escritos del agrónomo británico Arthur Young. Más allá que meramente informativos, estos materiales se hallaban atravesados por una profunda visión crítica.

El trasfondo de la visión agraria de Álvarez Guerra fue la fisiocracia. Conectaba con ello con el perfil propio que imprimió a su traducción de

9 Remitió al periódico veintidós colaboraciones, doce reseñas, seis discursos originales y cuatro instrucciones sobre cultivos y artes rurales. 
Rozier, que fue introducida en 1797 con un extenso prólogo de factura fisiócrata (Astigarraga-Usoz, 2007). No obstante, se imponía una labor de divulgación, pues él rechazaba la complejidad de la narrativa fisiócrata: «No se necesitan ni grandes cálculos ni la ostentación del lenguaje embrollado con que los economistas suelen dar a sus obras una importancia que no merecen; como si perdiesen algo en ser entendidos con solo leerlos» (1805: año II, $n$. XVI, 244).

Su cercanía a la fisiocracia era palpable en los extractos elegidos de Young. Esa selección estaba perfilada en función de los problemas de una agricultura como la extremeña o, más en general, la de las regiones españolas del interior; esto es, extensiva y anclada en los usos feudales, carente de comercio, basada en el monocultivo del grano y el empleo de «muchos brazos»; en suma, eventualmente de subsistencia y poco desarrollada. Uno de esos extractos estaba destinado a rebatir la idea de que los pueblos especializados en el cultivo de vid eran más pobres que los de los granos (ibid.: n. VIII, 84-97). En otro afloraba el debate sobre el tamaño de la propiedad agrícola, adelantado por la presentación de Young como un defensor del "gran cultivo» (ibid.: n. XIV, 94-107). Un tercero subrayaba los conocimientos de aritmética política de este para mostrar que la escasez de trigo en Gran Bretańa se debía a una legislación nociva y a que en las tres últimas décadas la población hubiera crecido más que el cultivo, por lo que urgía elegir un tamańo óptimo de cultivo (ibid.: n. IX, 157-166). En esos extractos traducidos, Álvarez Guerra corregía a Young introduciendo notas inspiradas por la fisiocracia. La utilización de este ideario, tanto su aparato conceptual (orden natural, producto neto, clases improductivas, circulación de las rentas), como normativo (libertad de cultivo, de precios, de comercio de granos, gran cultivo, combate contra los usos agrarios feudales, agricultura capitalista) resultaba especialmente evidente en otras de sus contribuciones a las Variedades: su extenso discurso original sobre los «Vicios del cultivo en Extremadura». Así pues, de la mano de Álvarez Guerra, las Variedades fueron el periódico español más cercano a la fisiocracia, aunque sus contenidos no procedieran de los órganos principales de la prensa fisiócrata, los Éphémérides du citoyen y el Journal de l'agriculture, du Commerce et des Finances.

\section{LA RESEÑA, INSTRUMENTO DE LA REFORMA SOCIOPOLÍTICA ILUSTRADA}

Durante el siglo XvıII fueron escritas las primeras reseñas de libros de economía en España. Con orígenes en los años cuarenta, este nuevo género floreció en las dos épocas de mayor brillantez de la prensa española: los años 
sesenta, por una parte, y entre 1780 y 1808, por otra. En la segunda se publicó el grueso de los casi dos centenares de reseñas identificadas en este trabajo ${ }^{10}$. Estas fueron consecuencia de la renovación de las principales cabeceras culturales y, en menor medida, sobre artes aplicadas. Fueron obra, por este orden, de Cladera, Ezquerra, Nifo y Saura. Estos cuatro grandes nombres del periodismo del setecientos español reunieron casi tres cuartas partes del total de las reseñas de autoría conocida.

Por otra parte, el fenómeno de las reseńas muestra que la economía política había alcanzado prestigio suficiente como para contar con un público propio. Se justificaba así su exitosa inclusión como un tópico más de las gacetas culturales. No es casual que el fin de los años ochenta, con su espíritu crítico con las costumbres sociales, coincidiera con la aparición de la prensa aderezada con noticias económicas. Tampoco lo es que los dos quinquenios más fructíferos en la publicación de reseñas coincidieran con dos momentos estelares del proceso de consolidación de la economía política en la esfera pública española: 1763-1767, cuando sus elites percibieron su importancia política, y 1786-1790, el momento en que se desarrolló una batalla ideológica de primer orden para la aceptación en la esfera pública de los principios de la sociedad comercial.

Efectivamente, las reseñas económicas, junto a otras nuevas formas expresivas o subgéneros literarios o paratextos, como los prólogos económicos y los discursos sobre la necesidad de los estudios económicos, fueron parte de un fenómeno de amplio espectro en el que convergen, especialmente desde la perspectiva de la historia intelectual, las doctrinas económicas, las ideas políticas y la creación de la esfera pública, la cual derivará en una opinión pública ajena a la visión peyorativa que de ella se tuvo en el Antiguo Régimen. En este sentido, el telón de fondo lo conforma el proceso de cambio del absolutismo al Estado liberal, cuyas líneas más definidas irán perfilándose durante el siglo XIX. Y en dicha transformación fueron el soporte de un discurso político renovador las ideas económicas, con su propuesta de «dulce comercio» y de mejora del bienestar material de la ciudadanía, frente a la tradicional y todavía hegemónica política de "conquista», en beneficio de la casa real gobernante y su sistema de poder y hacendístico.

Por todo ello, quizás, lo menos relevante de la producción de reseñas en la prensa española fuera su pluralismo, en tanto que los principales autores y escuelas de la Ilustración económica europea estuvieron representados. Salvo las Variedades, dominadas por los artículos de Álvarez Guerra afines a un agrarismo

10 Por décadas, el número de reseñas identificadas, representativo de la evolución cuantitativa referida, es el siguiente: 1730-1739 (1), 1760-1769 (45), 1770-1779 (1), 1780-1789 (67), 1790-1799 (56) y 1800-1805 (13). 
cercano a la fisiocracia, no existieron gacetas de reseńas monopolizadas doctrinalmente. Más significativo resulta que, a medida que pasaban los años, la reseña fuera mostrando gradualmente perfiles más sutiles. Su función era, sobre todo, informar e instruir, es decir, crear un público nuevo que se interesara por esa desconocida "ciencia del comercio». Ahora bien, en manos de Nifo la reseña pretendía favorecer la disposición de los lectores españoles hacia las novedades extranjeras; con Saura, promover su traducción; con Ezquerra y Manegat, familiarizar a esos lectores con la tratadística económica que estaba acompasando el desarrollo de las reformas borbónicas; con Cladera, imbuir a esos lectores de espíritu crítico, con el fin de proporcionarles argumentos que les ayudaran a pensar más allá de los lindes de esas reformas oficiales; y por último, con Álvarez Guerra, de manera ya explícita, para que pudieran incidir en la esfera política a través de la formación de la opinión pública. La elaboración de reseñas de libros de economía política enlazaba así con líneas políticas, sociales y culturales centrales de la Ilustración y se convertía en un producto genuino de ella.

\section{Bibliografía}

Álvarez Barrientos, J. (1990). El periodista en la España del siglo xvıII y la profesionalidad del escrito. Estudios de Historia Social, 51-53, 29-39.

Astigarraga, J. (2005a). I traduttori spagnoli di Filangieri e il risveglio del dibattito costituzionale (1780-1839). En A. Trampus (ed.). Diritti e Costituzione. L'opera di Gaetano Filangieri e la sua fortuna europea (pp. 231-290). Bolonia: Il Mulino.

- (2005b). La Fisiocracia en España: los Principes de la législation universelle (1776) de G. L. Schmid d'Avenstein. Historia Agraria, 37, 545-571.

- (2014). Forbonnais and the Discovery of the Science of Commerce in Spain (17551765). History of European Ideas, 40 (8), 1087-1107. Disponible en: https://doi.org/10 $.1080 / 01916599.2014 .968333$.

— (2018). Prensa económica de la Ilustración española (1758-1792). Studia HistóricaHistoria Moderna, 40 (2), 199-232. Disponible en: https://doi.org/10.14201/ shhmo2018402199231.

- y Usoz, J. (2007). Una alternativa fisiócrata al Informe de Ley Agraria de Jovellanos. Revista de Historia Económica, 25 (3), 427-458. Disponible en: https://doi.org/10.1017/ S0212610900000197.

- (2009). Política y Economía en el Análisis del Comercio del Trigo (1795) de Tomás Anzano. Hispania. Revista Española de Historia, 232, 395-421. Disponible en: https:// doi.org/10.3989/hispania.2009.v69.i232.109.

—_ (eds.) (2013). Le économie politique et la sphère publique dans le débat des Lumières. Madrid: Casa de Velázquez.

- (2019). Realpolitik, economía y propaganda en torno al parlamentarismo británico: el testamento político del almirante Byng (1780). Historia Constitucional, 20, 769-789. Disponible en: https://doi.org/10.17811/hc.v0i20.551. 
Astigarraga, J. y Zabalza, J. (2007). La fortuna del Essai sur la nature du commerce en général (1755), de Richard Cantillon, en la España del siglo xvirI. Investigaciones de Historia Económica, 7-3, 9-36. Disponible en: https://doi.org/10.1016/S1698-6989(07)70182-0.

Burke, P. (2017). A Social History of Knowledge. Cambridge: Polity Press.

Cavaillon, J. (2019). L 'édition sous Charles IV. Les annonces de librairie des journaux madrilènes (1789-1808). Aix-en-Provence: Presses universitaires de Provence.

Chartier, R. (1987). The cultural uses of print in early modern France. Princeton: Princeton University Press.

(1993). Libros, lecturas y lectores en la Edad Moderna. Madrid: Alianza Editorial.

- (1995). Espacio público, critica y desacralización en el siglo XVIII. Los orígenes culturales de la Revolución Francesa. Barcelona: Gedisa.

Díez Rodríguez, F. (1980). Prensa agraria en la España de la Ilustración. El Semanario de agricultura y artes dirigido a los párrocos (1797-1808). Madrid: Ministerio de Agricultura.

Domergue, L. (1981). Tres calas en la censura dieciochesca (Cadalso, Rousseau, Prensa periódica). Toulouse: Université Toulouse Le Mirail.

- (1982). Censure et Lumières dans l'Espagne de Charles III. París: Centre national de la recherche scientifique.

Elorza, A. (1970). La ideología liberal en la Ilustración española. Madrid: Taurus.

Enciso, L. M. (1958). Prensa económica del XVIII: El Correo Mercantil de España y sus Indias. Valladolid: Universidad de Valladolid.

Fernández Sebastián, J. (2015). From the «voice of the people» to the freedom of the press: the birth of public opinion. En J. Astigarraga (ed.). The Spanish Enlightenment revisited (pp. 203-233). Oxford: Voltaire Foundation.

Fuentes, J. F. (1990). El censor y el público. «Periodismo e Ilustración», número monográfico de Estudios de Historia Social, 52-53, 221-230.

Fuentes Quintana, E. (ed.) (2000). Economía y economistas españoles. Vol. III. La Ilustración. Barcelona: Galaxia Gutemberg-Círculo de Lectores.

Guinard, P. J. (1973). La presse espagnole de 1737 à 1791. París: Centre de Recherches Hispaniques.

Habermas, J. (1989). The Structural Transformation of the Public Sphere: An Enquiry into a Category of Bourgeois Society. Cambridge: Massachusetts Institute of Technology.

Hatin, E. (1859-1861). Histoire politique littéraire de la presse en France. Paris: Poulet Malassis et Broise.

Hüttner, S. (2009). Espiritu de los mejores diarios literarios que se publican en Europa (1787-1791). Índices (onomástico y de fuentes, de obras y toponímico). Frankfurt am Main: Peterlang.

Jovellanos, G. M. de [1786] (2008). Dictamen sobre la oportunidad de publicar una gaceta económica. En V. Llombart y J. Ocampo (eds.). G. M. de Jovellanos, Obras completas. Tomo X: escritos económicos (pp. 648-651). Oviedo: Instituto Feijoo de Estudios del Siglo XVIII.

Larriba, E. (2012). Las aspiraciones a la libertad de imprenta en la segunda mitad del siglo xvirI. En E. Larriba y F. Durán (eds.). El nacimiento de la libertad de imprenta (pp. 19-41). Madrid: Sílex.

- (2013). El público de la prensa en España a finales del siglo XVIII (1781-1808). Zaragoza: Prensas Universitarias de Zaragoza. 
— y Dufour, G. (1997). El Semanario de agricultura y artes dirigido a los párrocos (17971808). Valladolid: Ámbito.

Le Guellec, M. (2016). Presse et culture dans l'Espagne des Lumières. Madrid: Casa de Velázquez.

Llombart, V. (2000). El pensamiento económico de la Ilustración en Espańa. En E. Fuentes Quintana (ed.). Economía y economistas españoles. Vol. III. La Ilustración (pp. 7-89). Barcelona: Galaxia Gutemberg-Círculo de Lectores.

— (2004). Traducciones españolas de Economía Política (1700-1812): catálogo bibliográfico y una nueva perspectiva. Cyber Review of Modern Historiography, 9, 1-14.

López, F. (1990). Las obras extranjeras anunciadas en la Gaceta de Madrid. Estudio diacrónico. Elementos de una estadística. «Periodismo e Ilustración», número monográfico de Estudios de Historia social, 52-53, 303-311.

Maestre, J. M., Díaz, M. A. y Romero, A. (eds.) (2015). Francisco Mariano Nipho. El nacimiento de la prensa y de la crítica literaria periodística en la España del siglo XVIII. Madrid: Consejo Superior de Investigaciones Científicas.

Melton, J. van H. (2009). The rise of the public in Enlightenment Europe. Valencia: Universidad de Valencia.

Munck, Th. (2001). The Enlightenment. A comparative social history, 1721-1724. Barcelona: Crítica.

Nipho, F. M. (ed.) (1763). Diario Extranjero. Madrid.

Ocampo, J. (2013). El Semanario Económico (1765-1767): a la Ilustración por la utilidad. El Argonauta español, 10. Disponible en: http://argonauta.revues.org/1926.

Pérez, L. y Thébaud-Sorgier, M. (2008). Les techniques dans la presse d'annonces au XVIII ${ }^{c}$ siècle en France et en Angleterre. Réseaux d'information et logiques participatives. En P. Bret, K. Chatzis y L. Pérez (eds.). La Presse et les périodiques techniques en Europe (17501950) (pp. 11-50). Paris: L'Harmattan.

Robertson, J. (2005). The Case for The Enlightenment. Cambridge: Cambridge University Press.

- (2013). Enlightenment, Public Sphere and Political Economy. En J. Astigarraga y J. Usoz (eds.). L'Économie Politique et la sphère publique dans le débat des Lumières (pp. 9-32). Madrid: Casa de Velázquez.

Sáiz, M. D. (1983). Historia del periodismo en España. Vol. I. Los orígenes. El siglo XVIII. Madrid: Alianza.

Sempere, J. (1785-1789). Ensayo de una biblioteca de los mejores escritores de Carlos III. Madrid: Imprenta Real.

Sgard, J. (ed.) (1991). Dictionnaire des journaux (1600-1789). Disponible en: https://bit. ly/2S4XWIr.

Steiner, Ph (1996). Les grandes revues économiques de langue française au xvIIIeme siecle (1751-1776). En L. Marco (ed.). Les revues françaises d'économie politique XVIIIe-XIXe siècle (pp. 33-78). Paris: L'Harmatan.

Urzainqui, I. (1990). Los redactores del Memorial literario (1784-1808). Estudios de Historia Social, 52-53, 501-516.

— (1992). Crítica teatral y secularización: el Memorial literario (1784-1797). Bulletin Hispanique, 94, 203-243. 
(1995). Un nuevo instrumento cultural: la prensa periódica. En J. Álvarez Barrientos, F. López y I. Urzainqui (eds.). La República de las Letras en la España del Siglo XVIII (pp. 125-216). Madrid: Consejo Superior de Investigaciones Científicas.

- (2000). La crítica literaria en la prensa del siglo xvirI. Elementos de su discurso teórico. Bulletin Hispanique, 102 (2), 519-559. Disponible en: https://doi.org/10.3406/ hispa.2000.5054.

- (2009). La prensa en la época de Carlos IV: continuidades y cambios. En E. de Lorenzo (coord.). La época de Carlos IV (1788-1808) (pp. 87-112). Oviedo: Sociedad Española de Estudios del Siglo XVIII.

- (2012). Libertad de imprenta y prensa crítica a fines del siglo xvirI. En E. Larriba y F. Durán (eds.). El nacimiento de la libertad de imprenta (pp. 43-78). Madrid: Sílex.

Usoz, J. (2011). La "nueva política» ilustrada y la esfera pública: las introducciones a la Economía en el siglo xviı español. Revista de Estudios Políticos, 153, 11-46.

(2013). Los prólogos económicos y la esfera pública ilustrada en España. En J. Astigarraga y J. Usoz (eds.). L'Économie politique et la sphère publique dans le débat des Lumières (pp. 83-102). Madrid: Casa de Velázquez.

- (2015). Political Economy and the creation of the public sphere during the Spanish Enlightenment. En J. Astigarraga (ed.). The Spanish Enlightenment Revisited (pp. 105-127). Oxford: Voltaire Foundation.

Varela Hervías, E. (1966). Espiritu de los mejores diarios literarios que se publican en Europa, Madrid 1787-1791. Madrid: Sección de cultura "Nora».

Velasco, E. (2000). La Real Academia de la Historia en el siglo XVIII. Madrid: Centro de Estudios Políticos y Constitucionales. 